\title{
Democratização do ensino por meio da prática avaliativa: três cenários em aulas de matemática
}

\author{
André Luis Trevisan \\ Marcele Tavares Mendes \\ Anna Flávia Magnoni Vieira
}

\section{Resumo}

Este texto ancorou-se em uma perspectiva de avaliação enquanto prática de investigação e oportunidade de aprendizagem, tendo em vista sua exploração em caráter formativo, como possível caminho para democratização do ensino e do conhecimento elaborado em sala de aula. Para tanto, apresentaram-se três cenários avaliativos vivenciados a partir das práticas dos autores, por meio de da utilização de instrumentos de avaliação: a prova escrita; a prova escrita em fases e o relatório escrito. Por meio da discussão acerca desses cenários, foi possível evidenciarmos possibilidades de uma prática avaliativa enquanto meio para democratização da prática pedagógica.

Palavras-chave: Avaliação da aprendizagem escolar. Prova escrita. Prova em fases. Relatório escrito. 


\title{
Democratization of teaching by means of assessment practice: three scenarios in mathematics classes
}

\author{
André Luis Trevisan \\ Marcele Tavares Mendes \\ Anna Flávia Magnoni Vieira
}

\section{Abstract}

This text was anchored in a learning perspective as a practice of research and learning, in view of its evolution as a lesson. The evaluation of the evaluation of self-evaluation, from the use of the evaluation of instruments; a writing written in phases and the written report. Through the dispensation of new scenarios, it was possible to evidence possibilities of an evaluation action while the democratization of the pedagogical practice.

Keywords: Evaluation of school learning. Written test. Phase testing. Written report. 


\section{Introdução}

A conquista do direito à educação, enquanto luta política e histórica da sociedade, garantida de forma universal pela Constituição, tem se intensificado na atualidade. Em seu Capítulo III (Seção I, Da Educação), define os papéis de cada ente federativo no cenário desse direito. Em seu artigo 205, aponta que a "educação, direito de todos e dever do Estado e da família, será promovida e incentivada com a colaboração da sociedade, visando ao pleno desenvolvimento da pessoa, seu preparo para o exercício da cidadania e sua qualificação para o trabalho" (BRASIL, 1988, on-line).

De acordo com a Lei de Diretrizes e Bases da Educação (BRASIL, 1996, on-line), a oferta de educação escolar pública é dever do estado, e deverá ser efetivado mediante a garantia de "padrões mínimos de qualidade de ensino definido como a variedade e quantidade mínimas, por aluno, de insumos indispensáveis ao desenvolvimento do processo de ensinoaprendizagem”. A garantia do direito à educação básica com qualidade, que diz respeito ao acesso, à universalização da alfabetização e à ampliação da escolaridade e das oportunidades educacionais, é reforçada por meio das 11 primeiras metas do Plano Nacional de Educação. Em especial, a meta sete prevê o fomento à "qualidade da educação básica em todas as etapas e modalidades, com melhoria do fluxo escolar e da aprendizagem” (BRASIL, 2014, p. 10).

Embora as responsabilidades estejam definidas, a realidade educacional mostra um distanciamento entre o direito à educação e o cotidiano da sala de aula. Ferreira e Almeida (2014, p. 37) lembram que a "história da educação carrega consigo um passado fundado na discriminação das minorias e, por consequência, na geração das desigualdades e de exclusão”.

Nesse contexto, a avaliação escolar tem sido um dos processos centrais para disciplinar e hierarquizar os sujeitos, realçando um caráter antidemocrático da escola e um papel enquanto ferramenta de exclusão social. Conforme Esteban (2008, p. 9), “apesar das diferenças e desigualdades existentes, os resultados dos vários exames internacionais são aceitos como informações fidedignas sobre a qualidade da educação em cada um dos países que deles participam e como legítimos para orientar as estratégias educacionais a se colocar em prática”.

Nossa Base Nacional Comum Curricular (BNCC) menciona, mas não discute, outro caráter e papel para o processo de avaliação escolar, ao apontar que a avalição escolar deve ser deve ser um meio formativo que leva "em conta os contextos e as condições de aprendizagem, tomando tais registros como referência para melhorar o desempenho da escola, dos professores e dos alunos" (BRASIL, 2018, p. 17).

Nosso intuito, neste artigo, é explorar uma avaliação com natureza formativa como um caminho desejável para avaliação do conhecimento produzido no contexto da sala de aula. Reconhecemos que não é suficiente mencionar que, conforme Esteban (2008, p. 12), é preciso 
explorá-lo, "expressando com clareza as características que deve assumir a fim de participar de um amplo processo de democratização da dinâmica pedagógica”.

Neste artigo subsidiamos teoricamente uma caracterização de aspectos de uma prática avaliativa enquanto prática investigativa e oportunidade de aprendizagem, ou seja, de natureza formativa. Após essa discussão, apresentamos três cenários na intenção de utilizá-los para evidenciar essa prática avaliativa enquanto meio para democratizar a prática pedagógica, diminuindo a distância entre o direito à educação e o contexto da sala de aula. Finalizamos com as nossas considerações finais, seguidas das referências bibliográficas.

\section{Avaliação e exclusão}

A avaliação é um elemento essencial para pensarmos a questão da garantia ao direito à educação, visto que, conforme apontam Buriasco, Ferreira e Ciani (2009, p. 70 - 71), ainda "hoje, na escola, a execução do rito de avaliar [...] parece ser suficiente para fazer acreditar que se cumpriu o esperado desse mito: medir e classificar de maneira precisa os alunos".

Essas autoras lembram que o ato mais frequentemente associado ao termo avaliação no cotidiano escolar é a aplicação de uma prova escrita. Nesse contexto, em que o mito da crença na precisão da nota sobressai-se, o rito de avaliar acaba por se constituir em uma prática que confere uma validade ilusória ao mito da possibilidade do exercício da precisão e da justiça. A partir desse exercício de precisão e de justiça, avaliar acaba por ser um julgamento, marcado segundo Esteban (2003), por uma ótica da homogeneidade.

Nesse modelo avaliativo predominante em nossas escolas, os altos índices de reprovação (presentes desde a origem do processo de escolarização) começaram a ser questionados tanto por agentes educativos quanto pela própria sociedade civil, de forma mais sistemática e ampla, na segunda metade do século XX, e formas alternativas de organizar o ensino e a não utilização da reprovação como procedimento pedagógico, contribuíram para esse debate (JACOMINI, 2014).

Ao analisar a avaliação escolar no regime de progressão continuada, essa autora lembra que, as primeiras discussões sobre essa temática ocorreram no Brasil na década de 1920, no contexto de uma proposta de não reprovação na passagem da primeira para a segunda série do Ensino Primário na rede estadual paulista, tendo recebidos duras críticas e, assim, não prosperando.

A escola primária paulista manteve os altos índices de reprovação até meados da segunda metade do século XX, quando políticas de contenção da reprovação escolar foram implementadas [...]. A discussão sobre reprovação anual e progressão continuada voltou ao cenário educacional brasileiro na década de 1960, protagonizada por Dante Moreira Leite e Almeida Júnior. Estes educadores qualificaram o debate analisando a reprovação do ponto de 
vista pedagógico e educacional. Argumentaram que a reprovação encerra contradição ao processo educativo e implica na não garantia do direito à educação, na medida em que corrobora a evasão (JACOMINI, 2014, p. 810).

Infelizmente, experiências de ensino não seriado nas décadas seguintes nem sempre foram avaliadas de forma criteriosa, tendo sido interpretadas, principalmente pelos professores da Educação Básica, como malsucedidas, contribuindo para reforçar argumentos a favor da seriação e reprovação anual, reforçando assim o caráter exclusório da avaliação.

Segundo Barlow (2006), enquanto atividade humana socializada, a avaliação está cercada de mitos e ritos, e muitas das fantasias que dizem respeito à ação de avaliar devem-se ao seu aspecto social e à forte carga afetiva por ele comportada. Ao recuperar a etimologia da palavra aponta que, "a palavra évaluation parece significar a ação de fazer aparecer o valor de um indivíduo ou objeto" (BARLOW, 2006. p.12, grifo do autor). Em língua latina, os valores são formas de ser (no sentido de tornar-se cada vez mais válido - eficaz, pleno de sentido), de modo que

avaliar é demarcar o grau de êxito e, ao mesmo tempo, as possibilidades ainda abertas de "ser melhor", de uma realização. E igualmente, dar vazão a um sentido, revelar em uma conduta a parcela de inteligibilidade já adquirida e a que falta adquirir (BARLOW, 2006, p. 12).

O que muitas vezes se observa nas práticas de salas de aula é uma avaliação que, numa melhor hipótese, revela a "parcela de inteligibilidade já adquirida”, menosprezando, ou mesmo ignorando, aquela que se "falta adquirir", as "possibilidades ainda abertas de 'ser melhor", o conhecimento heterogêneo. Assim, "apesar das inúmeras tentativas de evitar que a avaliação seja 'contaminada' pela desordem, o cotidiano nos informa que a heterogeneidade é um dos fios com que se tece o processo avaliativo" (ESTEBAN, 2000, p. 3).

É fundamental pensar a avaliação como um processo que permite aos professores ter informações a respeito do conhecimento já elaborado pelos estudantes, mas também que revela o que precisa "ainda ser feito", inclusive oferecendo indícios se sua proposta de trabalho, as metodologias de ensino que adota e as ações em sala de aula estão oportunizando aos estudantes a elaboração desse conhecimento.

Além disso, a avaliação não deve ser vista como um processo que envolve apenas o professor, mas diversos outros elementos, como o próprio conteúdo da disciplina, o material, o apoio e trabalho pedagógico, mas, principalmente, os estudantes. Para esses últimos (assim como para os professores), a avaliação deve oferecer elementos que contribuam para a (re) elaboração constante de conhecimentos, e não apenas como um jogo de "tudo ou nada", no qual se busca a nota (o valor, no sentido atribuído usualmente nas práticas escolares) como único fim. Os erros devem tornar-se desencadeadores de discussões que oportunizem aos 
estudantes compreendê-los para que, assim, possam ultrapassá-los.

\section{Avaliação enquanto prática de investigação e oportunidade de aprendizagem}

Tornar a avaliação parte dos processos de ensino e de aprendizagem implica exercêla ao longo de toda ação de formação, torná-la permanente, para ir além da meta de identificar se os estudantes "adquiriram" conhecimentos que lhes foram propostos para a meta de preparar, orientar, aperfeiçoar a ação do estudante e do próprio professor. Assim, as práticas de sala de aula devem ocorrer em "um contexto orientado, guiado por situações que desafiem e que os estudantes desejem fazê-las e discuti-las, situações que os conduzem no uso de seus conhecimentos e que exigem busca de novas alternativas ou conhecimentos para a resolução" (MENDES; TREVISAN; BURIASCO, 2012, p. 11).

Segundo Luckesi (2011b, p.149, grifo do autor), a avaliação da aprendizagem escolar precisa ser entendida como um "ato de investigar a qualidade de seu objeto de estudo $e$, se necessário, intervir no processo da aprendizagem”. Para esse autor, a investigação produz uma compreensão da realidade e desvela a trama das relações que a constituem. Além disso, conhecer é uma ação de investigar a realidade e, como consequência, possibilita sustentar uma ação adequada e satisfatória (intervenção). Sendo assim, a avaliação da aprendizagem, enquanto ação de investigação e de intervenção deve oferecer bases consistentes para a decisão e o agir, quando necessário.

Trata-se de mudar o foco do meramente estar "certo ou errado" (pedagogia do exame) para a investigação do modo como os estudantes "lidam com determinado problema, ou seja, como o interpretam, que estratégias utilizam para resolvê-lo, como expressam matematicamente suas idéias" (BURIASCO; FERREIRA; CIANI, 2009, p.77).

Para Hadji (1994, p. 63), a avaliação dita formativa tem por objetivo: contribuir para melhorar a aprendizagem em curso, informando o professor sobre as condições em que está a decorrer essa aprendizagem, e instruindo o aprendente sobre o seu próprio percurso, os seus êxitos e as suas dificuldades.

Ora, ao informar o aluno acerca das condições em que ocorre a aprendizagem, o professor está tomando a avaliação como um ato de comunicação, ação essa fundamentada no próprio percurso do estudante e que se reflete a partir dos encaminhamentos dados por ambos, frente aos êxitos e às dificuldades observados.

Ao encontro de uma perspectiva de avaliação formativa, os trabalhos desenvolvidos no interior do GEPEMA ${ }^{27}$, apontam a avaliação como instrumento de formação presente no

${ }^{27 G r u p o ~ d e ~ E s t u d o ~ e ~ P e s q u i s a ~ e m ~ E d u c a c ̧ a ̃ o ~ M a t e m a ́ t i c a ~ e ~ A v a l i a c ̧ a ̃ o, ~ a t r e l a d o ~ a o ~ P r o g r a m a ~ d e ~ P o ́ s-G r a d u a c ̧ a ̃ o ~ e m ~}$ Ensino de Ciências e Educação Matemática da Universidade Estadual de Londrina (UEL), na qual os dois primeiros autores desenvolveram suas teses. 
processo educativo tanto como meio de diagnóstico dos processos de ensino e de aprendizagem da Matemática quanto como instrumento de investigação da prática pedagógica. As análises desenvolvidas envolvendo a produção escrita de estudantes são realizadas sob a perspectiva da avaliação como prática de investigação e como oportunidade de aprendizagem. Para Buriasco, Ferreira e Ciani (2009, p.75),

[...] assumir a avaliação da aprendizagem escolar como prática de investigação implica colocar-se em uma postura de investigação, o que exige, por parte do professor, o reconhecimento da existência de uma multiplicidade de caminhos percorridos pelos estudantes, a admissão de que, tal como eles, está em constante processo de elaboração de conhecimento.

Para essas autoras, tomar a avaliação como prática de investigação é uma alternativa por meio da qual se pode buscar informações a respeito do modo como estudantes e professores mobilizam seu repertório na elaboração de conhecimento, o que requer uma mudança do olhar e das intenções a ela comumente associados.

Compreender a avaliação e executá-la como um projeto intencional e planejado no cotidiano das aulas implica, entre outras coisas, pensar os instrumentos de avaliação e definilos de acordo com as possibilidades teórico-metodológicas que oferecem para avaliar. Luckesi (2011a, p.304) lembra que "todos os instrumentos de coleta de dados para a avaliação da aprendizagem hoje existentes e utilizados em nossas escolas [...] são úteis para o exercício da prática avaliativa da aprendizagem”.

A seleção de instrumentos de avaliação deve ocorrer durante o processo de planejamento de ensino, buscando adequar os recursos de avaliação aos objetivos previstos, aos conteúdos estabelecidos e às atividades propostas para a aprendizagem. É desejável que o professor varie os suportes (observação, auto-avaliação e registros escritos, entre outros) e os instrumentos, com vistas a coletar uma maior quantidade de dados e assim, ter informações para (re) planejar seu trabalho e orientar a aprendizagem dos alunos e, conforme Barlow (2006), evitar penalizar os estudantes que sentem dificuldade na utilização deste ou daquele.

Outro aspecto é o "erro". Em uma perspectiva de avaliação a serviço dos processos de ensino e de aprendizagem, o "erro" passa a ser visto como recurso para evidenciar e potencializar o heterogêneo, o quão dinâmico deve ser o processo de aprender. Uma forma de superar obstáculos na aprendizagem da matemática é o diálogo entre professor e aluno em torno da problematização do erro. Cury e Silva (2008) propõem uma metodologia para análise de erros tomando como base a análise de conteúdo proposta por Bardin (1979) de acordo com as seguintes etapas: pré-análise, exploração do material e tratamento dos resultados, assim indica que uma possibilidade de trabalhar com os resultados de pesquisas sobre os erros cometidos por alunos, são atividades que exploram os conteúdos nos quais os alunos têm 
maiores dificuldades de aprendizagem ou com os quais desenvolvem habilidades matemáticas, de maneira geral.

Em uma prática avaliativa que oportuniza a aprendizagem consideramos que "erro e acerto não são posições com valores desiguais, mas expressões dos diferentes sujeitos, processos e conhecimentos que dialogam na produção de novas possibilidades, de saber e de fazer" (ESTEBAN, 2012, p. 591).

\section{A composição de Cenários}

Acreditamos que um processo enquanto prática de investigação e oportunidade de aprendizagem não se configura plenamente em uma sala de aula sem um repensar de toda a prática pedagógica. Em nossa prática nas aulas de Cálculo Diferencial e Integral, defendemos que tais ambientes sejam pautados em episódios de resolução de tarefas (adaptação da expressão shift problem lessons, proposta por Palha et al (2013) e Palha, Dekker e Gravemeijer (2015), nas quais os alunos tenham um papel ativo trabalhando quando possível em grupos e em tarefas não precedidas da apresentação de conceitos e/ou definições, que sejam desencadeadoras de discussões e que contribuam para elaborações conceituais (TREVISAN; MENDES, 2018).

Um dos objetivos específicos desse artigo, após apresentação teórica dos elementos que configuram a avaliação enquanto prática de investigação e oportunidade de aprendizagem, é discutir 3 cenários avaliativos vivenciados em nossas práticas a partir da utilização dos instrumentos de avaliação: a "Costumeira" Prova Escrita, a Prova Escrita em Fases e o Relatório Escrito. A discussão desses cenários tem por objetivo explorar a heterogeneidade do conhecimento; "entre" o certo e o errado, apresentar algumas possibilidades para potencializar práticas avaliativas que favoreçam a aprendizagem, que democratizem o acesso a educação de qualidade.

\section{Cenário 1: A Costumeira Prova Escrita}

Os sujeitos envolvidos neste cenário foram treze alunos (repetentes) do Curso de Engenharia de Materiais, e ingressos no segundo semestre de 2016 da disciplina de Cálculo Diferencial e Integral I. Para a coleta dos dados utilizaram-se como instrumento, as provas escritas $^{28}$ dos sujeitos envolvidos. E para a análise dos dados observaram-se os erros cometidos pelos alunos em suas resoluções, optando pelas informações por meio do registro escrito; desta forma o trabalho seguiu uma abordagem qualitativa no agrupamento destes dados.

O ponto de partida foi a realização da leitura de cada prova, e a partir daí pode-se

${ }^{28}$ Uma prova escrita que fora proposta para ser resolvida individualmente, sem consulta a materiais de apoio e com tempo limitado (prova em uma fase). ISSN 2526-2882 
verificar estratégias de resoluções adotadas pelos alunos para lidarem com situações que exigiam a realização de procedimentos algébricos, assim como os erros cometidos em suas resoluções. A partir daí, procurou-se agrupar estes erros, no sentido de observar com qual frequência apareciam, buscando deste modo evidenciar possíveis obstáculos relacionados aos conteúdos estudados durante a Educação Básica. Assim, agruparam-se os erros segundo 3 categorias, todas envolvendo um tratamento algébrico, sendo elas:

1. Simplificação de frações algébricas;

2. Manipulações algébricas envolvendo propriedade distributiva;

3. Construção de gráficos;

E por fim, discutiu-se acerca da análise dos erros observados por meio das resoluções dos alunos, no sentido de conscientizar e problematizar o erro, como possível prática de investigação e oportunidade de aprendizagem. É importante salientar que as provas analisadas já haviam passado pela correção do professor responsável pela disciplina, portanto em alguns recortes das resoluções dos alunos apareceram às correções do professor. A Figura 1 revela erros do primeiro agrupamento, Simplificação de frações algébricas.

Figura 1: Erros envolvendo simplificação de frações algébricas
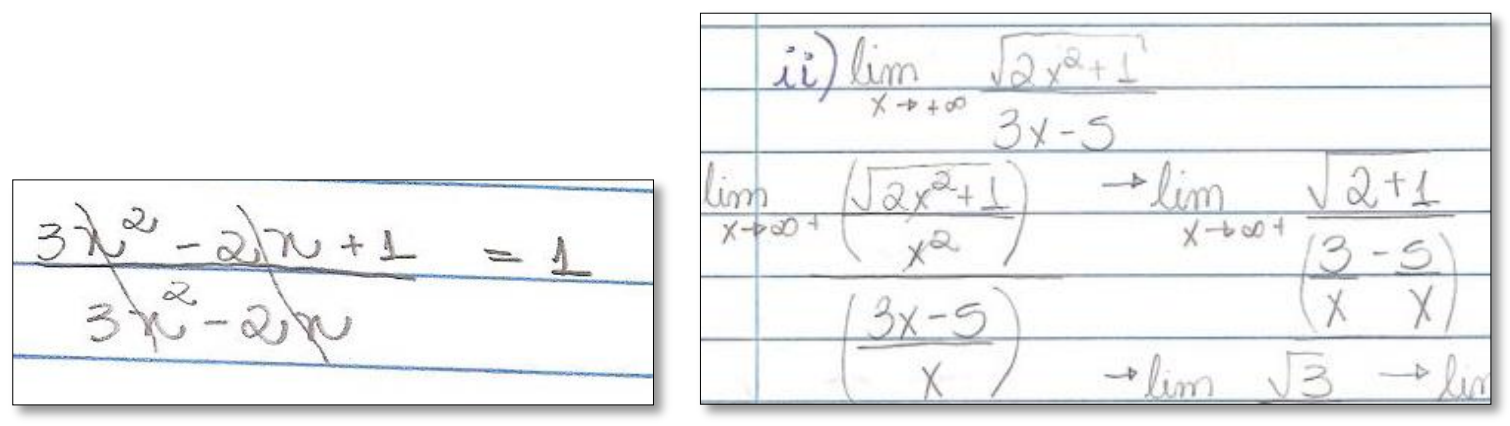

Fonte: autores.

É possível observar em ambas resoluções que os alunos realizaram de forma equivocada a simplificação das frações algébricas; inferimos que os alunos utilizaram propriedades fazendo analogia à operação da multiplicação entre frações, a qual permite a simplificação dos termos semelhantes do numerador com os do denominador. Cabe salientar, que as resoluções apresentadas na figura são de alunos diferentes, no entanto, este tipo de erro é comum entre os alunos.

Nesta direção, propomos como uma possível estratégia de ensino por parte do professor, a conscientização e problematização do erro e não mera classificação da resolução do aluno, em certa ou errada. Alinhado a essa ideia, Cury e Cassol (2004) e Cury e Silva (2008) 
destacam que os erros podem indicar caminhos importantes a serem seguidos no sentindo de inserir novas metodologias para o ensino da Matemática.

Os sujeitos que realizaram essas provas foram alunos de Cálculo Diferencial e Integral, o equívoco é considerado conhecimento matemático básico. Entretanto, apenas afirmar que nossos alunos não possuem esses conhecimentos não os fazem melhores, apenas o excluem. Ao invés de puni-los (notas baixas que vão impedi-los de melhorar, de serem aprovados por conta do rendimento da primeira prova, mesmo que evoluam ao longo do período letivo) ou excluí-los, por que não os colocar em situação de aprendizagem, para então observar em novas oportunidades, novos cenários, como lidam com simplificação de expressões algébricas.

Dando continuidade aos agrupamentos, a Figura 2 ilustra equívocos com relação à propriedade distributiva.

Figura 2: Erros envolvendo manipulações algébricas
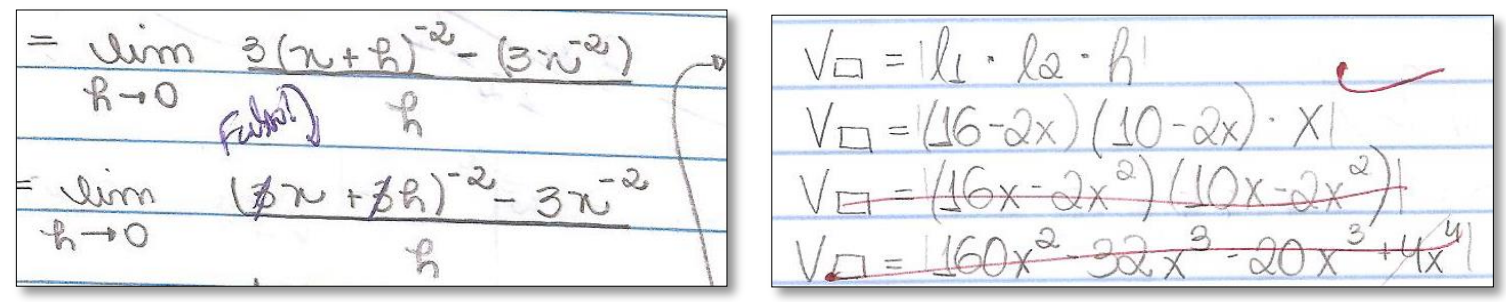

Fonte: autores.

Na resolução no lado esquerdo da Figura 2, o aluno opera distribuindo a multiplicação corretamente, porém como há uma potenciação, e esta deveria ter sido resolvida anteriormente à distributiva, o aluno resolve de forma errada. Já na resolução da direita, o aluno multiplica o fator $x$ uma vez a mais do que deveria.

Analisando os erros cometidos pelos alunos, verificamos que apesar de ambos se enquadrarem na mesma categoria (distributiva) são erros distintos, por esse motivo julga-se importante a análise e a reflexão sobre os erros cometidos pelos alunos, uma vez que, evidenciam somente o que os alunos não sabem, mas, eles fornecem informações sobre como os alunos aprendem e compreendem determinado conteúdo. Nessa ótica, o erro deixa de ser simplesmente casual e, passa a ser considerado como parte do processo de construção do conhecimento (CURY; SILVA, 2008). Outra vez o professor tem a oportunidade de criar um caminho dialógico de aprendizagem, a produção escrita revela a urgência do professor "falar" sobre o assunto, esses alunos precisam de oportunidades de revelar "como" sabem e lidam com o conhecimento matemático, e a partir disso, regular suas produções. Por fim, o terceiro agrupamento, Construção de gráficos, é representado pela Figura 3. 
Figura 3: Erros envolvendo construção de gráficos

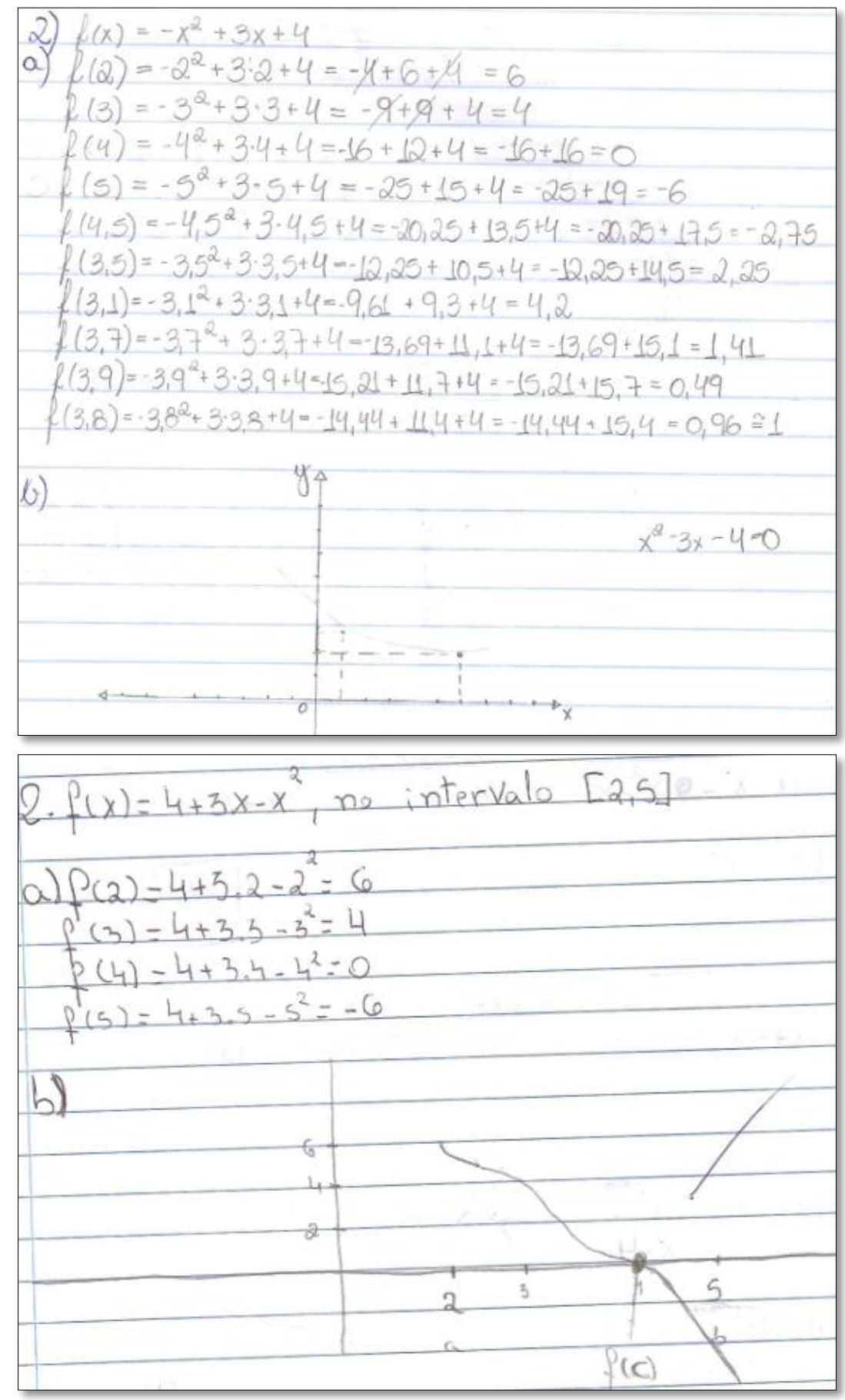

Fonte: autores.

Nota-se em ambas resoluções presentes na Figura 3 estratégias adotadas pelos alunos na tentativa de esboçarem gráficos de funções polinomiais do $2^{\circ}$ grau. Na resolução do lado esquerdo, o aluno opta por substituir alguns pontos para em seguida desenhá-los no plano cartesiano, como possível esboço do gráfico da função. É possível inferir neste caso que não houve erro no momento de tais substituições, poderia até ser uma possibilidade de construção, no entanto, o problema maior é que o aluno não demonstra o conhecimento dos elementos 
básicos para a construção do gráfico, não reconhece que o coeficiente "a” quando negativo, resulta em uma parábola côncava para baixo.

Na resolução do lado direito, percebe-se a mesma situação, o aluno também não demonstra o conhecimento do comportamento do gráfico de uma função do $2^{\circ}$ grau. Nesses casos, cabe ao professor reconhecer que o erro apresenta-se devido a insuficiência de estratégias de resolução para o problema, podendo deste modo propor novas tarefas que oportunizem a exploração de determinados conteúdos, neste caso, Função do $2^{\circ}$ grau.

É fundamental que o professor, ao invés de tonar a prova escrita como uma mera ferramenta de aferição, passe a pensá-la como um meio para questionar-se a respeito do que "os seus estudantes estão aprendendo, que entendimentos estão tendo do que está sendo trabalhado em sala de aula, do que já sabem, que dificuldades encontram, e o que pode ser feito para auxiliá-los na superação destas” (BURIASCO; FERREIRA; CIANI, 2009, p. 7).

Neste Cenário 1, a costumeira prova escrita, torna-se meio de diagnóstico, ela favorece recolher informações do que é preciso falar para que esse aluno de Cálculo Diferencial e Integral venha a ter oportunidade de desenvolver-se e de progredir no contexto da disciplina, de saber quais habilidades e competências básicas precisam ser trabalhadas. Dar oportunidade a um aluno, não é apenas matriculá-lo, esse é apenas o primeiro passo.

\title{
Cenário 2: A Prova em Fases, um meio de comunicação
}

A chamada prova em duas fases, cujas referências são encontradas em trabalhos de De Lange $(1987,1999)$ e Van Den-HeuvelPainhuizen (1996), é uma prova escrita realizada em dois momentos: uma primeira etapa na sala de aula, com tempo limitado, e uma segunda fase, num tempo maior, em geral, a ser feita em casa. Em nossos trabalhos, temos investigado propostas de desdobramento da prova em mais fases, enquanto meio para (re)significação da prova escrita, a qual tem sido chamada simplesmente prova em fases.

\begin{abstract}
Na perspectiva por nós adotada, trata-se de uma prova escrita, resolvida individualmente e em sala de aula, contendo questões associadas aos objetivos de aprendizagem a serem explorados ao longo de determinado espaço de tempo (um bimestre, um semestre, um ano), a qual os estudantes têm acesso desde a primeira fase (portanto, antes mesmo das aulas na qual serão explorados tais objetivos). Os próprios estudantes podem reconhecer/escolher quais questões resolver em cada fase podendo alterar as resoluções, nas etapas subsequentes, sempre que julgarem necessário (TREVISAN; MENDES, 2015, p. 52).
\end{abstract}

Trazemos a pesquisa de Mendes (2014), uma das autoras desse artigo, enquanto um Cenário de avaliação que favoreceu o professor estabelecer uma comunicação com os alunos, assim como entre os alunos. Apesar do cenário também ter sido desenvolvido com alunos de Cálculo Diferencial e Integral, o enfoque não é a aprendizagem matemática, mas o como o ISSN 2526-2882 
aluno comunicou-se a partir do lidar com esse instrumento, o como o tornou-se agente regulador de sua aprendizagem.

Neste estudo, a professora e 48 alunos matriculados na disciplina de Cálculo Diferencial e Integral de uma universidade federal paranaense, realizaram uma prova escrita em 10 fases. A problemática foi investigar a utilização da prova escrita em fases como recurso para a regulação da aprendizagem. Em cada uma das fases a professora construiu questionamentos, intervenções escritas a partir da produção dos estudantes. Não houve julgamento de certo e errado ao longo das fases, o interesse era o desenvolvimento do aluno e o seu modo de lidar com cada uma das questões e intervenções escritas.

Esses alunos ao serem questionado sobre 'o que estavam achando em fazer uma prova em fases' apresentaram elementos que permitiram reconhecer que se sentiram seguros, assistidos e que em diálogo com o professor. Um exemplo de resposta é apresentado no Quadro 1.

Quadro 1: Opinião de um aluno acerca do trabalho com a prova em fases "Acho que [fazer a prova] faz com que nos preocupemos com o que temos dificuldade, faz
com que nos preocupemos também em buscar conhecimentos, enfim a correr atrás do
prejuízo e estudar. É bom, as vezes não penso em tudo o que faço ou que fiz no exercício,
apenas faço e assim temos que pensar o porque de tudo que fazemos e quais as palavras
que vou utilizar para que não fique confuso, você já deve ter percebido que eu me confundo
toda com as palavras." (EM11CDI21, resposta a Q1). Fonte: Mendes (2014, p. 194)

A segurança, assistência e o diálogo são funções anexas da regulação da aprendizagem (Hadji, 1994). A prova em fase favorece o aluno compreender o seu ritmo de aprendizagem e as suas necessidades. Um ponto de destaque é a individualidade, cada aluno preocupa-se com as suas dificuldades, o professor elabora intervenções individualizadas. As intervenções escritas individualizadas possuem o potencial em reconhecer o heterogêneo, o conhecimento não linear.

\section{Cenário 3: A Carta para a Tia - um relatório escrito}

O Terceiro cenário baseia-se na utilização de um relatório escrito elaborado por alunos matriculados na disciplina de CDI. No Quadro 2, segue o enunciado da tarefa entregue aos alunos, adaptada da proposta apresentada por Santos (2005): produzir um relatório escrito (que utilizava como suporte uma carta destinada a um parente ou amigo), explicitando o que aprenderam ao finalizar um conteúdo, no intuito de explicitar tanto os processos por eles vivenciados quanto os produtos de sua aprendizagem, constituindo-se, portanto, como um instrumento de avaliação a serviço da aprendizagem. 
Quadro 2: Enunciado da tarefa entregue aos alunos

Construa uma carta para sua "tia" explorando os conceitos estudados nas aulas de Cálculo nesses dois primeiros meses de aula. O objetivo é que você construa um veículo para dialogar com você mesmo e com sua "tia", que auxilie a organizar seu pensamento, ajudando-o a estudar melhor. Você escreverá livremente, aproveitando esse momento para pensar sobre seu processo de aprendizagem. Sua carta não será uma cópia do caderno, nem de livros. É uma atividade essencialmente pessoal, devendo contemplar também aspectos emocionais e afetivos ("gostei imensamente de estudar derivada", "pra que raios inventaram essa tal de integral?”). A carta deve ser recheada de exemplos e imagens, de preferência de sua própria criação, ilustrando os conceitos trabalhados em sala de aula, acompanhados de explicações. Também é fundamental incluir reflexões do tipo: o que entendi sobre este conceito? Por quê? O que não entendi? Por quê? Seu trabalho deve ter entre três e cinco laudas matemáticas.

Fonte: Autores.

A Figura 4 é um trecho de uma das cartas entregue ao professor, o aluno revela que compreende que lidar com funções compostas é uma competência base para lidar com a Regra da Cadeia. Mais uma vez, o professor tem a oportunidade de conhecer seu aluno, gerar situações de aprendizagem; como possibilidades: uma lista sobre funções compostas, uma conversa em horário de atendimento, pedir para o monitor trabalhar tal tema. O importante é que o aluno deu o sinal, ele comunicou algo para então o professor decidir o melhor meio de orientá-lo.

Figura 4: trecho de carta entregue ao professor

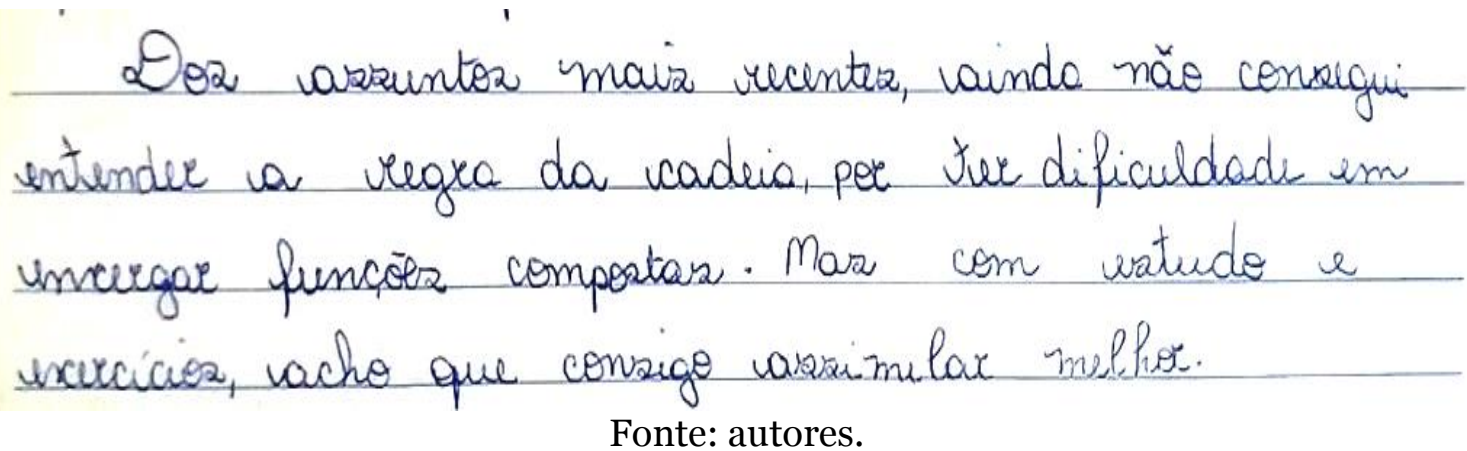

Já a Figura 5 traz uma produção que revela o que o aluno compreendeu do conceito de derivada, com isso, o professor tem a oportunidade de indagar-se sobre o que "os seus estudantes estão aprendendo, que entendimentos estão tendo do que está sendo trabalhado em sala de aula, do que já sabem, que dificuldades encontram, e o que pode ser feito para auxiliá-los na superação destas” (BURIASCO, FERREIRA, CIANI, 2009, p. 78). 
Figura 5: trecho de carta entregue ao professor

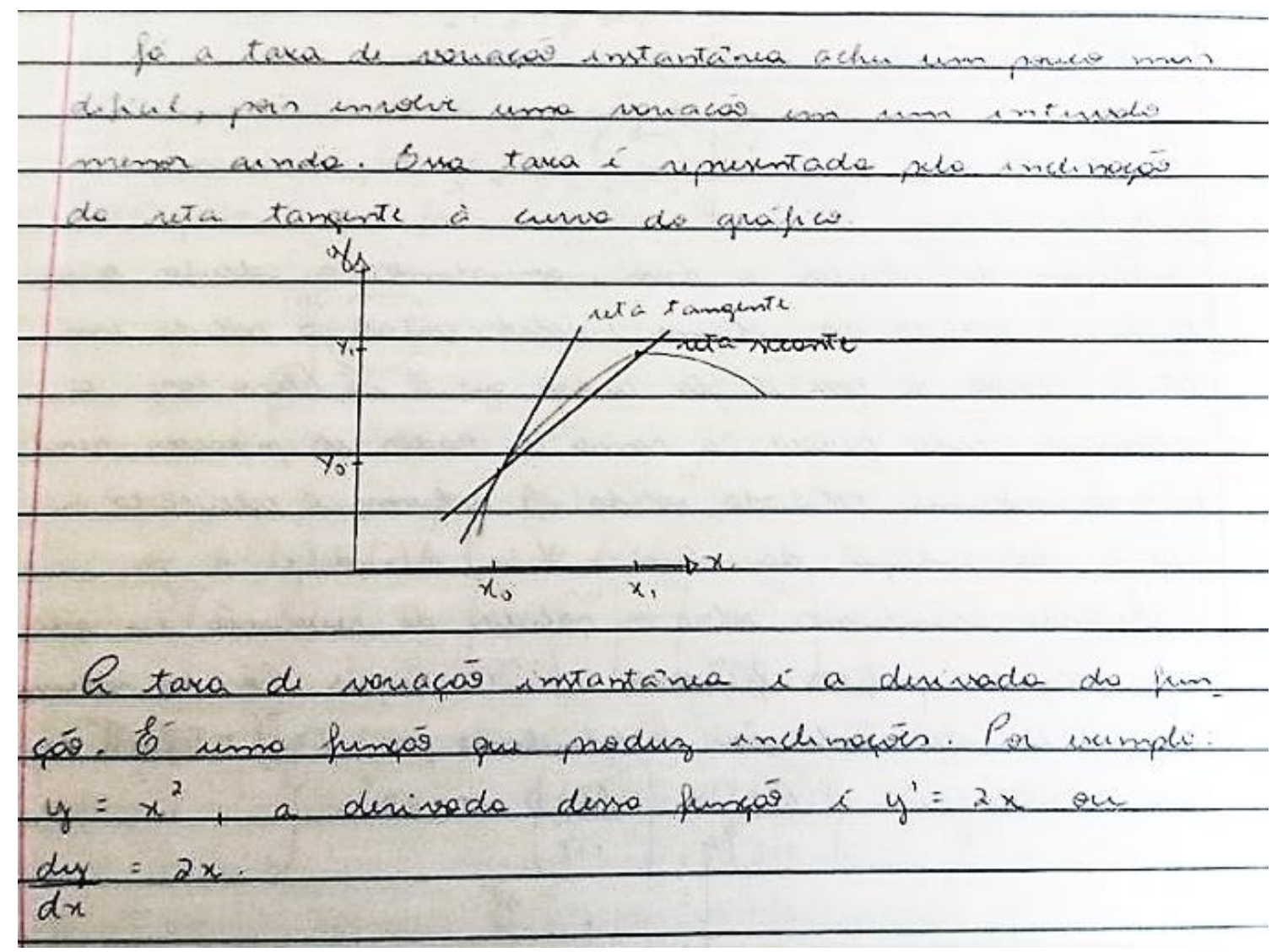

Fonte: autores.

Cabe ao professor criar estratégias, questionando oralmente, para refinar o entendimento apresentado. Neste caso, o professor precisa conversar com o aluno sobre a taxa ser uma inclinação, o que é um equívoco. O aluno precisa de um feedback, de informações úteis sobre as etapas vencidas e as dificuldades encontradas em suas produções, esse também é um meio de integralizá-lo, de torná-lo para além de um aluno matriculado nas estatísticas de políticas educacionais.

\section{Considerações finais}

Entender a avaliação da aprendizagem escolar como prática de investigação significa mudar o olhar quanto a esse processo, deixando de ser visto como um elemento de ameaça e punição passando a ser visto como oportunidade de aprendizagem.

Nesse contexto em que se busca fazer da prática avaliativa um ato de investigação e de intervenção, como também tornar o aluno cada vez mais autônomo sobre seus processos de aprendizagem, torna-se necessário sempre refletir e discutir sobre a potencialidade dos instrumentos de avaliação. Portanto, a discussão em torno dos cenários apresentados neste artigo, nos revela a prática avaliativa como meio para democratizar a prática pedagógica. 
O primeiro cenário evidenciou a conscientização e problematização do erro, por parte do professor, e não mera classificação da resolução do aluno, em certa ou errada. Os "erros" passam a ser vistos não como algo que o aluno ainda não sabe, mas como indícios de um conhecimento parcial, como um elemento inerente ao processo de elaboração do conhecimento, como um caminho na busca do acerto para reconstruir o que não foi aprendido.

Já o segundo, apresentou a prova em fases, considerada um instrumento de avaliação que favorece ao aluno revelar mais do que sabe, ao invés daquilo que não sabe, com diversos desdobramentos, adaptável à realidade de cada sala de aula. Ainda que, num primeiro momento, o estudante não saiba resolver ou tenha dificuldades de compreensão dos conteúdos e/ou dos processos envolvidos, constantemente deve-se incentivá-lo a apresentar suas tentativas, que sofrerão alguma interferência/intervenção do professor, em uma proposta constante de reavaliação.

E por fim, a análise da produção escrita aponta que, por meio da prova em fases, o professor tem a oportunidade de guiar os estudantes em seus processos de aprendizagem, favorecendo, para cada um, o desenvolvimento de diferentes níveis de competência e um meio que favorece a conquista do direito à educação e em favor da aprendizagem.

\section{Referências}

BARDIN, L. Análise de conteúdo. 3. ed. Lisboa: Edições 70, 1977.

BARLOW, M. Avaliação escolar: mitos e realidades. Porto Alegre: Artmed, 2006.

BRASIL. Constituição da República Federativa do Brasil de 1988. Brasília, DF, 1988. Disponível em <http://www.planalto.gov.br/ccivil_03/Constituicao/Constituicao.htm>. Acesso em 24 fev. 2019.

BRASIL. Lei n. 9 394, 26 de dezembro de 1996. Estabelece as diretrizes e bases da educação nacional. Brasília, DF, 1996. Disponível em <http://www.planalto.gov.br/ccivil_03/Leis/L9394.htm>. Acesso em 24 fev. 2019.

BRASIL. Plano Nacional de Educação. Brasília, DF, 2014. Disponível em <http://www.observatoriodopne.org.br/uploads/reference/file/439/documentoreferencia.pdf >. Acesso em 24 fev. 2019.

BRASIL. Base Nacional Comum Curricular (BNCC). Educação é a Base. Brasília, MEC/CONSED/UNDIME, $2017 . \quad$ Disponível em <www.basenacionalcomum.mec.gov.br>. Acesso em 24 fev. 2019.

BURIASCO, R. L. C.; FERREIRA, P. E. A.; CIANI, A. B. Avaliação como prática de investigação (alguns apontamentos). Bolema, UNESP - Rio Claro, v. 22, n. 33, p. 69-96, 2009.

CURY, H. N; CASSOL, M. Análise de erros em cálculo: uma pesquisa para embasar mudanças. 
Acta Scientiae, v. 6, n. 1, p. 27-36, 2004.

CURY, H. N., SILVA, P. N. Análise de erros em resolução de problemas: uma experiência de estágio em um curso de Licenciatura em Matemática. Revista Brasileira de Ensino de Ciência e Tecnologia, v.1, p.85- 97, 2008.

DE LANGE, J. Mathematics, Insight and Meaning. Utrecht: OW \&OC, 1987.

. Framework for classroom assessment in mathematics. Utrecht: Freudenthal Institute and National Center for Improving Student Learning and Achievement in Mathematics and Science, 1999. Disponível em: <http://fi.uu.nl/publicaties/literatuur/6279.pdf>. Acesso em 16 jan. 2016.

ESTEBAN, M. T. Avaliar: ato tecido pelas imprecisões do cotidiano. In: GARCIA, R.L. (Org.). Novos olhares sobre a alfabetização. São Paulo: Cortez, p.175-192, 2000.

ESTEBAN, M. T. A avaliação no cotidiano escolar. In: ESTEBAN, M. T. et al. Avaliação: uma prática em busca de novos sentidos. 5 ed. Rio de Janeiro: DP\&A, p. 7-28, 2003.

Esteban, M. T. Silenciar a polissemia e invisibilizar os sujeitos: indagações ao discurso sobre a qualidade da educação. Revista Portuguesa de Educação, v. 21, n.1, p.5-31, 2008.

ESTEBAN, M. T. Considerações sobre a política de avaliação da alfabetização: pensando a partir do cotidiano escolar. Revista Brasileira de Educação, Rio de Janeiro, v. 17, n. 51, p. 573-592, set./dez. 2012.

FERREIRA, C. J. A.; ALMEIDA, F. F. de. Avaliação escolar continuada: uma ousadia em favor da aprendizagem. Revista Interação, 13. ed., ano VIII, v.01, n.01, p. 31-41, 2014.

HADJI, C. A avaliação, regras do jogo: das intenções aos instrumentos. Tradução Júlia Lopes Ferreira e José Manuel Cláudio. 4. ed. Portugal: Porto, 1994.

JACOMINI, M. A.. Avaliação da aprendizagem em tempos de progressão continuada: o que mudou? Um estudo de teses e dissertações sobre o tema (2000-2010). Ensaio: avaliação e políticas púbicas em Educação, Rio de Janeiro, v.22, n. 84, p. 807-828, jul./set. 2014. Disponível em <http://www.scielo.br/pdf/ensaio/v22n84/a10v22n84.pdf>.

LUCKESI, C. Avaliação da aprendizagem: componente do ato pedagógico. São Paulo, SP: Cortez, 2011a.

Avaliação da aprendizagem escolar: estudos e proposições. 22. ed. São Paulo, SP: Cortez, 2011b.

MENDES, M. T. Utilização da Prova em fases como recurso para aprendizagem em aulas de Cálculo. 2014. Tese (Doutorado em Ensino de Ciências e Educação Matemática) - Universidade Estadual de Londrina, Londrina, 2014.

MENDES, M. T.; TREVISAN, A. L.; BURIASCO, R. L. C. Possibilidades de intervenção num contexto de ensino e avaliação em matemática. Em Teia: Revista de Educação 
Matemática e Tecnológica Iberoamericana, v. 3, p. 1-13, 2012.

PALHA, S.; DEKKER, R.: GRAVEMEIJER, K.; VAN HOUT-WOLTERS, B. Developing shift problems to foster geometrical proof and understanding. The Journal of Mathematical Behavior. Springer, v.32, p.141-159, 2013.

PALHA, S.; DEKKER, R.: GRAVEMEIJER, K. The effect of shift-problem lessons in the mathematics classroom. Internacional Journal os Science and Mathematics Education. Ministry of Science and Technology, Taiwan, v.13, p.1589-1623, 2015.

TREVISAN, A. L., MENDES, M. T.. A Prova Escrita como Instrumento de Avaliação em Aulas de Matemática. Educação Matemática em Revista (São Paulo), v.45, p.48 - 55, 2015 .

TREVISAN, A. L., MENDES, M. T.. A Prova Escrita como Instrumento de Avaliação em Aulas de Matemática. Educação Matemática em Revista (São Paulo), v.45, p.48 - 55, 2015 .

TREVISAN, A. L.; MENDES, M. T. Ambientes de ensino e aprendizagem de Cálculo Diferencial e Integral pautados em episódios de resolução de tarefas: uma proposta de caracterização. Revista Brasileira de Ensino e Tecnologia, Ponta Grossa, v. 11, n. 1, p. 209-277, 2018.

VAN DEN HEUVEL-PANHUIZEN, M. V. D. Assessment and Realistic Mathematics Education. Utrecht: CD- $\beta$ Press/FreudenthalInstitute, Utrecht University, 1996.

\section{Biografia Resumida}

André Luis Trevisan: Licenciado em Matemática (Unicamp - 2005), Bacharel em Matemática Aplicada e Computacional (Unicamp 2005) e Mestre em Matemática Aplicada (Unicamp - 2008). Doutor em Ensino de Ciências e Educação Matemática (UEL 2013). Atualmente, cursando pós-doutorado na UFABC. Atuou como professor de Matemática nos anos iniciais e finais do Ensino Fundamental e no Ensino Médio. É professor efetivo da Universidade Tecnológica Federal do Paraná, e docente permanente dos Programas de Mestrado Profissional em Ensino de Matemática (câmpus Londrina/Ponta Grossa) e do Doutorado em Ensino de Ciência e Tecnologia (câmpus Ponta Grossa). Áreas de interesse: Educação Matemática na Educação Básica e Ensino Superior, Tarefas matemáticas, Ensino de Cálculo Diferencial e 
Integral, Aprendizagem Profissional do Professor.

Link Lattes: http://lattes.cnpq.br/3166010229447391

e-mail: andrelt@utfpr.edu.br

Marcele Tavares Mendes: Possui graduação em matemática pela

Universidade Estadual de Londrina (2003), mestrado em Matemática pela Universidade Estadual de Maringá (2006) e doutorado em Ensino de Ciências e Educação Matemática pela Universidade Estadual de Londrina (2014). Desde 2009 é docente da Universidade Tecnológica Federal do Paraná, campus Londrina. Docente do Departamento de Matemática e Programa de Mestrado Profissional em Ensino de Matemática - câmpus Londrina/Cornélio Procópio. Áreas de interesse: Educação Matemática na Educação Básica e Ensino Superior, Avaliação da Aprendizagem, Tarefas matemáticas, Ensino de Cálculo Diferencial e Integral.

Link Lattes: http://lattes.cnpq.br/3399032085207656

e-mail: marceletavares@utfpr.edu.br

Anna Flávia Magnoni Vieira: Possui graduação pela Faculdade de Apucarana (2010), especialização em Educação Matemática (2011) pela Universidade Estadual de Londrina e mestrado (2018) pela Universidade Tecnológica Federal do Paraná-LD e membro do Grupo de Estudos e Pesquisa sobre a Formação de Professores que Ensinam Matemática (GEPEFOPEM). Atualmente é professora de matemática da rede particular de ensino, Colégio Platão. Tem experiência na área de Matemática, no Ensino Fundamental, Ensino Médio e Cursinho preparatório para vestibular.

Link Lattes: http://lattes.cnpq.br/7885791424874224

e-mail: anna_flavia_magnoni@hotmail.com 